\title{
Elevated TSH in adults treated for hypothyroidism is associated with increased mortality
}

\author{
Amit Akirov ${ }^{1,2}$, Hannah Gimbel2 ${ }^{2}$ Alon Grossman ${ }^{2,3}$, Tzipora Shochat ${ }^{4}$ and \\ Ilan Shimon ${ }^{1,2}$ \\ ${ }^{1}$ Institute of Endocrinology, Rabin Medical Center-Beilinson Hospital, Petah Tikva, Israel, ${ }^{2}$ Sackler School \\ of Medicine, Tel Aviv University, Tel Aviv, Israel, ${ }^{3}$ Internal Medicine E, and ${ }^{4}$ Statistical Consulting Unit, \\ Rabin Medical Center-Beilinson Hospital, Petah Tikva, Israel
}

Correspondence should be addressed to A Akirov

Email

amit.akirov@gmail.com

\begin{abstract}
Context: Numerous studies investigated the link between hypothyroidism and mortality, but a definite conclusion is hard to reach as these were limited by a number of factors, including age of participants, comorbidities and single measurement of thyroid function.

Objective: To evaluate the association between TSH and fT4 levels and mortality in patients with levothyroxinetreated hypothyroidism.

Design and setting: Observational data of hospitalized patients (2011-2014). TSH and fT4 levels obtained between at least 30 days after discharge and until death or end of follow-up were collected. Median TSH and fT4 levels were stratified into categories.

Patients: In total, 611 patients with treated hypothyroidism, aged $60-80$ years ( $72 \%$ females, mean age $71 \pm 6$ years) were included in the study.

Main outcome measure: All-cause mortality up to 66 months after discharge, by TSH and fT4 categories.

Results: During follow-up, the average numbers of TSH and fT4 measurements were $5.5 \pm 3.8$ and $2.5 \pm 4.2$ per patient respectively. Mortality rates were $28 \%, 29 \%$ and $54 \%$ with median TSH of $0.5-2.5,2.5-5.0$ and $5.0-10.0$ IU/L respectively. Adjusted hazard ratios for mortality with median TSH between 5.0 and $10.0 \mathrm{IU} / \mathrm{L}$ were $2.3(95 \% \mathrm{Cl}$ : 1.6-3.4) and 2.2 (95\% Cl: 1.6-3.2) compared with patients with TSH between $0.5-2.5 \mathrm{IU} / \mathrm{L}$ and $2.5-5 \mathrm{IU} / \mathrm{L}$ respectively. There was no difference in mortality between patients with median fT4 10-15 or 15-20 pmol/L.

Conclusion: In treated hypothyroid adult patients and serial measurements of thyroid function tests, median TSH levels of 5-10IU/L are associated with increased mortality with no effect of fT4 levels. Treatment should aim at achieving
\end{abstract} euthyroidism to improve survival.

\section{Introduction}

Thyroid function disorders are common in the general population, and the prevalence of overt hypothyroidism ranges between $1 \%$ and $7 \%(1,2)$. Although autoimmune thyroiditis is the most common cause of hypothyroidism in elderly subjects, other causes, such as drugs, neck radiotherapy, thyroidectomy or radioiodine therapy are frequently observed in this population (3). Previous studies in elderly patients have
() 2017 European Society of Endocrinology Printed in Great Britain suggested an association between thyroid dysfunction and mortality $(4,5)$.

Numerous studies investigated the link between subclinical and overt hypothyroidism and mortality, with conflicting results $(4,6,7,8,9,10,11,12,13,14,15,16,17)$. Waring et al. reported that a single measurement of thyroidstimulating hormone (TSH) and free T4 (fT4) did not predict the mortality in older men (7). Iglesias et al. investigated 
thyroid function in hospitalized patients and demonstrated an association between alteration in thyroid function tests during hospitalization and long-term mortality in elderly patients (1). Furthermore, a recent study reported that higher TSH and lower fT4 concentrations within the normal range are associated with lower risk of mortality in elderly patients (18). Although the association between TSH levels and mortality was analyzed in a number of metaanalyses for patients with subclinical hypothyroidism, there is no analysis available for patients with overt hypothyroidism $(19,20,21)$. A definite conclusion is hard to reach as previous studies were limited by a number of factors, including age of participants, adjustment for comorbidities, single measurement of thyroid function and therapeutic intervention.

Unlike previous studies, focusing mainly on patients with subclinical hypothyroidism, we sought to examine the relationships, individually and combined, between TSH, fT4 and all-cause mortality in levothyroxine-treated adults with hypothyroidism.

\section{Methods}

Historical prospective data were extracted from the electronic medical records of all patients who were admitted to the medical wards in Rabin Medical Center, Israel, between January 2011 and January 2014. Inclusion criteria were age 60-80 years with a previous diagnosis of hypothyroidism with levothyroxine treatment. A diagnosis of hypothyroidism was based on either a recorded diagnosis of hypothyroidism in the medical records, defined by ICD-10 code (E03.2-E03.9), or on a documented chronic use of levothyroxine. Patients with thyroid cancer were excluded from the analysis. All patients were followed for at least 18 months and up to 66 months.

Rabin Medical Center, encompassing Beilinson and Golda-Hasharon campuses, is a tertiary-care facility with more than 1300 beds. Most of the admissions to the 10 medical wards are through the emergency department, and all patients' data are recorded in electronic medical charts, based on the same database platform used in community primary care facilities.

Electronic records of all adult hypothyroid patients treated with levothyroxine were manually searched for TSH and fT 4 measurements between at least 30 days after discharge and until the end of follow-up. Levels of TSH were measured by chemiluminescence assay (IMMULITE 2000; Siemens Corp) for which the normal range limits are $0.55-4.78 \mathrm{IU} / \mathrm{L}$. fT4 upper and lower limits are
$10-20 \mathrm{pmol} / \mathrm{L}$ (22). These are the normal values defined by the central laboratory at Clalit Health Services. Thyroid function blood tests were performed in an ambulatory setting, between 07:00 and 09:00 h (patients were not informed to take levothyroxine after the blood test).

Patients without documented TSH levels after discharge were excluded.

Median, maximal, minimal and average TSH levels between at least 30 days after discharge and until death or the end of follow-up were classified into the following categories: (1) <0.5, (2) $0.5-2.5$, (3) 2.5-5.0, (4) 5.0-10.0 and (5) $>10 \mathrm{IU} / \mathrm{L}$. fT 4 levels were classified into 4 categories: (1) $<10$, (2) $10-15$, (3) $15-20$ and (4) $\geq 20 \mathrm{pmol} / \mathrm{L}$.

Mortality data were obtained from the hospital's mortality database, updated from the Ministry of the Interior Population Registry. Mortality data were collected until July 1, 2016.

Data regarding comorbidities, according to diagnoses as defined in the medical records, were collected. Data included malignancy, hyperlipidemia, hypertension, ischemic heart disease, chronic heart failure, chronic renal failure, cerebrovascular disease, chronic obstructive pulmonary disease, asthma, interstitial lung disease and inflammatory bowel disease.

\section{Statistical analysis}

The statistical analysis was generated using SAS Software, version 9.4 of the SAS System for PC, Copyright 2002-2012. SAS Institute Inc. and all other SAS Institute Inc. products or service names are registered trademarks or trademarks of SAS Institute Inc., Cary, NC, USA. Continuous variables are presented by mean \pm S.D., categorical variables are presented by $(n, \%)$. Analysis of variance (ANOVA) was used to compare continuous variables between study groups. Logistic regression was used to compare dichotomous variables between study groups. Kaplan-Meier analysis was used to assess the effect of TSH, fT4 or their combination on survival.

Cox proportional hazards model was used to assess the above survival adjusted for study variables, including age, gender, smoking, alcohol, malignancy, chronic renal failure, ischemic heart disease, congestive heart failure, hypertension, chronic renal failure and cerebrovascular disease. Two-sided $P$ values less than 0.05 were considered statistically significant.

Complete data were obtained for all the study variables, other than BMI and smoking. No imputation for missing data was done because missing at random cannot be assumed. 


\section{Results}

\section{Study cohort}

Among 1250 patients aged $60-80$ years with levothyroxine-treated hypothyroidism, the final cohort included 611 patients, predominantly female (440 (72\%)), with a mean (s.D.) age of $71 \pm 6$ years. Excluded were 616 patients without documented TSH levels after discharge, as well as 23 patients with thyroid cancer (Fig. 1).

During the follow-up, a total of $3370 \mathrm{TSH}$ measurements and 1516 fT4 measurements were recorded. The average number of TSH measurements was

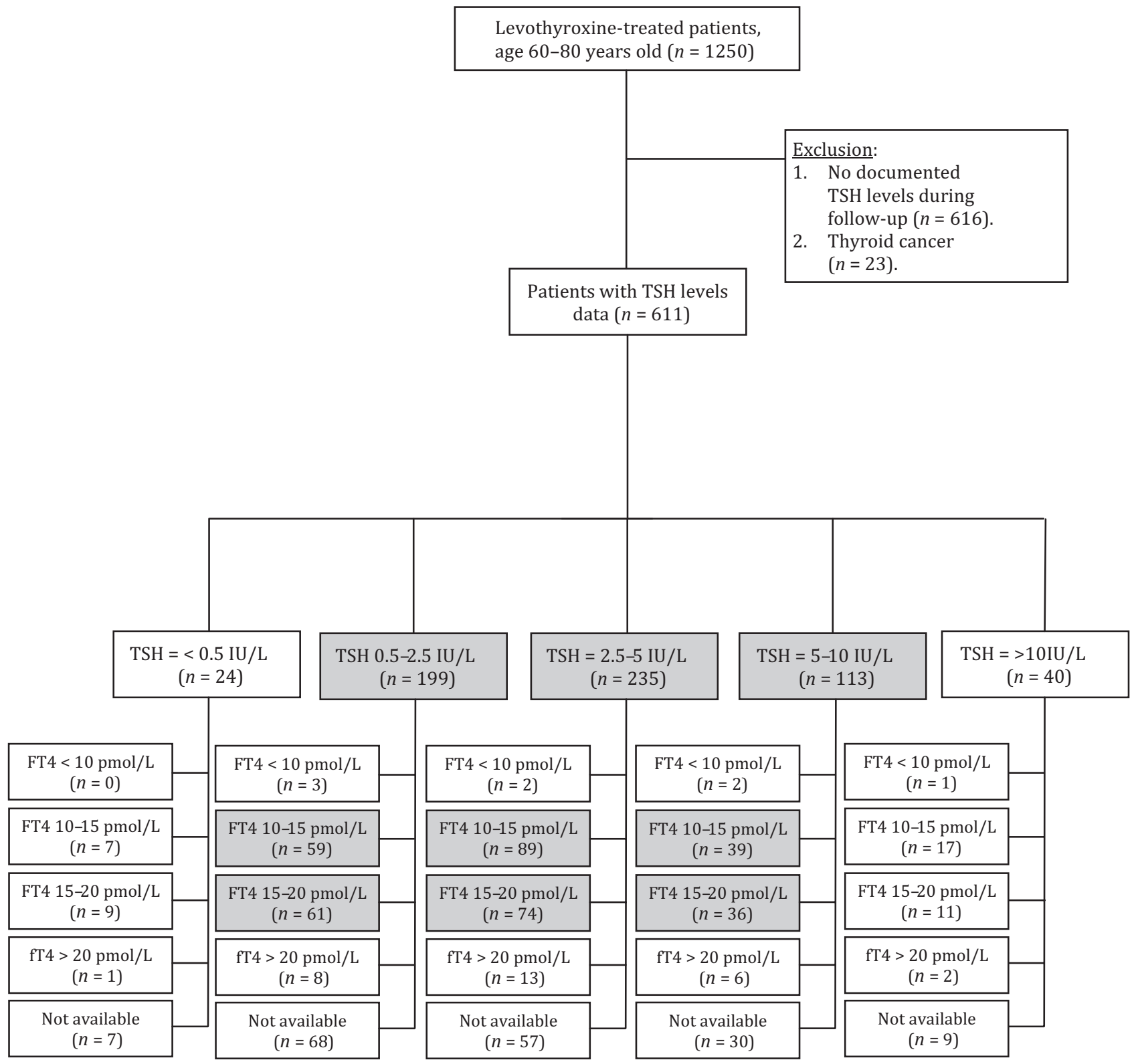

\section{Figure 1}

Patient flow diagram. The records of all patients aged 60-80 years admitted for any cause to the Rabin Medical Center's medical wards between January 2011 and January 2014 were screened as described in the text. 
Table 1 Baseline characteristics. Baseline characteristics and comorbidities of patients according to median TSH levels during follow-up.

\begin{tabular}{l} 
Patient characteristics \\
\hline Age, mean (median) \\
Men, $n(\%)$ \\
Smoking (\%) \\
Alcohol (\%) \\
BMI, mean \\
Number TSH measurements, mean (median) \\
Co-morbidities, $n$ (\%) \\
Malignancy \\
Hypertension \\
Diabetes mellitus \\
Ischemic heart disease \\
Congestive heart failure \\
Cerebrovascular disease \\
Chronic renal failure \\
Chronic obstructive pulmonary disease \\
\hline
\end{tabular}

\begin{tabular}{c}
\hline TSH $=\mathbf{0 . 5 - 2 . 5}(n=199)$ \\
\hline $71 \pm 6(71)$ \\
$47(27 \%)$ \\
$14(8 \%)$ \\
$1(1 \%)$ \\
$30 \pm 14$ \\
$5.7 \pm 4(5)$ \\
$27(14 \%)$ \\
$101(51 \%)$ \\
$72(36 \%)$ \\
$54(27 \%)$ \\
$21(11 \%)$ \\
$14(7 \%)$ \\
$21(11 \%)$ \\
$9(5 \%)$
\end{tabular}

\begin{tabular}{c}
\hline $\mathbf{T S H}=\mathbf{2 . 5 - 5 . 0}(n=235)$ \\
\hline $71 \pm 6(72)$ \\
$72(42 \%)$ \\
$12(6 \%)$ \\
$0(0 \%)$ \\
$30 \pm 20$ \\
$5.5 \pm 4(5)$ \\
$38(16 \%)$ \\
$137(58 \%)$ \\
$91(39 \%)$ \\
$56(24 \%)$ \\
$18(8 \%)$ \\
$28(12 \%)$ \\
$30(13 \%)$ \\
$11(5 \%)$
\end{tabular}

\begin{tabular}{c}
\hline TSH = 5-10 $(n=113)$ \\
\hline $72 \pm 5(74)$ \\
$34(20 \%)$ \\
$10(11 \%)$ \\
$0(0 \%)$ \\
$29 \pm 6$ \\
$5.3 \pm 5(4)$ \\
$27(24 \%)^{*}$ \\
$73(65 \%)^{*}$ \\
$53(47 \%)$ \\
$34(30 \%)$ \\
$13(12 \%)$ \\
$19(17 \%)^{*}$ \\
$17(15 \%)$ \\
$1(1 \%)$
\end{tabular}

BMI, body mass index; fT4, free T4.

${ }^{\star} P<0.05$ compared to the group of patients with median TSH levels between 0.5 and $2.5 \mathrm{IU} / \mathrm{L}$.

$5.5 \pm 3.8$ tests per patient. Most patients (77\%) had at least three TSH measurements during the follow-up. Every measurement of an fT4 level included a concomitant TSH level measurement also; hence, the average number of fT4, or fT4 together with TSH level, was $2.5 \pm 4.2$ measurements per patient.

Median TSH levels measured between at least 30 days after discharge and until death or the end of follow-up were classified as follows: TSH $<0.5 \mathrm{IU} / \mathrm{L}, 24$ patients ( $4 \%$ ); TSH $0.5-2.5 \mathrm{IU} / \mathrm{L}, 199$ patients (33\%); TSH 2.5-5.0 IU/L, 235 patients (38\%); TSH 5.0-10.0IU/L, 113 patients (18\%) and TSH $>10.0 \mathrm{IU} / \mathrm{L}, 40$ patients $(7 \%)$. Because of the small number of patients with TSH $<0.5 \mathrm{IU} / \mathrm{L}$ and TSH $>10 \mathrm{IU} / \mathrm{L}$, data were not analyzed for these groups. There was no significant difference between the numbers of TSH measurements among the various groups of patients with the different median TSH levels (Table 1).

Baseline characteristics and comorbidities, described in Table 1 , were generally similar between the TSH categories, with no difference in mean age, BMI, gender, smoking, alcohol, diabetes, chronic renal failure, congestive heart failure, ischemic heart disease and chronic obstructive pulmonary disease. Malignancy, hypertension and cerebrovascular disease were more common in patients with TSH levels between 5 and $10 \mathrm{IU} / \mathrm{L}$, compared to patients with TSH between 0.5 and $2.5 \mathrm{IU} / \mathrm{L}(P<0.05)$.

\section{TSH levels and mortality}

The median follow-up until death or end of follow-up was 997 days, with a mean follow-up of $1247 \pm 201$ days in the group of patients who survived until the end of follow-up and $555 \pm 367$ days in the group of patients who died during the follow-up. The average number of TSH measurements in patients still alive at the end

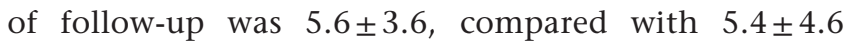
in those who died during the follow-up. Respective average numbers of fT4 measurements were $2.6 \pm 2.5$ and $2.3 \pm 2.9$.

During the follow-up, 184 patients with median TSH levels between 0.5 and $10 \mathrm{IU} / \mathrm{L}$ died (184/547 patients, $34 \%$ ), with mortality rates of $28 \%$ (56/199 patients), $29 \%$ (67/235 patients) and 54\% (61/113 patients) recorded in patients with median TSH of $0.5-2.5,2.5-5.0$, and 5.0-10.0 IU/L, respectively.

Unadjusted hazard ratio of all-cause mortality compared to median TSH levels between 0.5 and $2.5 \mathrm{IU} / \mathrm{L}$ was significant in subjects with median TSH levels between 5.0 and $10.0 \mathrm{IU} / \mathrm{L}(2.5,95 \% \mathrm{CI}$, 1.8-3.6), but not with TSH levels between 2.5 and 5.0IU/L. This held true following adjustments for age, gender, malignancy, ischemic heart disease, congestive heart failure, hypertension, diabetes, chronic renal failure and cerebrovascular disease, with a hazard ratio of 2.3 (95\% CI, 1.6-3.4) in those with median TSH levels between 5.0 and 10.0 IU/L (Table 2).

The unadjusted and adjusted hazard ratios with median TSH levels between 5.0 and 10.0 IU/L compared to median TSH levels between 2.5 and $5.0 \mathrm{IU} / \mathrm{L}$ were 2.4 (1.7-3.4) and 2.2 (1.6-3.2), respectively.

The trend was similar with mean TSH levels and minimal TSH levels during follow-up (Fig. 2). 
Table 2 Mortality and hazard ratio for mortality.

\begin{tabular}{|c|c|c|c|}
\hline & $\mathrm{TSH}=0.5-2.5$ & $\mathrm{TSH}=\mathbf{2 . 5}-5.0$ & $\mathrm{TSH}=5-10$ \\
\hline Total patients & 199 & 235 & 113 \\
\hline Mortality, $n(\%)$ & $56(28 \%)$ & $67(29 \%)$ & $61(54 \%)$ \\
\hline \multicolumn{4}{|c|}{ Comparison to $\mathrm{TSH}=0.5-2.5$} \\
\hline Unadjusted HR & & $1.1(0.7-1.5)$ & $2.5(1.8-3.6)$ \\
\hline Adjusted HR* & & $1.0(0.7-1.5)$ & $2.3(1.6-3.4)$ \\
\hline \multicolumn{4}{|c|}{ Comparison to $\mathrm{TSH}=2.5-5.0$} \\
\hline Unadjusted HR & & & $2.4(1.7-3.4)$ \\
\hline Adjusted HR* & & & $2.2(1.6-3.2)$ \\
\hline \multicolumn{4}{|l|}{$\mathrm{fT} 4=10-15$} \\
\hline Total patients & $59(16 \%)$ & $89(25 \%)$ & $39(11 \%)$ \\
\hline Mortality, $n(\%)$ & $16(27 \%)$ & $22(25 \%)$ & $18(46 \%)$ \\
\hline \multicolumn{4}{|c|}{ Comparison to $\mathrm{TSH}=0.5-2.5$} \\
\hline Unadjusted HR & & $0.9(0.5-1.8)$ & $2.0(1.0-3.9)$ \\
\hline Adjusted HR* & & $0.9(0.5-1.8)$ & $2.2(1.0-4.3)$ \\
\hline \multicolumn{4}{|c|}{ Comparison to $\mathrm{TSH}=2.5-5.0$} \\
\hline Unadjusted HR & & & $2.1(1.1-3.9)$ \\
\hline Adjusted HR* & & & $2.2(1.2-4.3)$ \\
\hline \multicolumn{4}{|l|}{$\mathrm{fT} 4=15-20$} \\
\hline Total patients & $61(17 \%)$ & $74(21 \%)$ & $36(10 \%)$ \\
\hline Mortality, $n(\%)$ & $15(25 \%)$ & $19(26 \%)$ & $18(50 \%)$ \\
\hline \multicolumn{4}{|c|}{ Comparison to $\mathrm{TSH}=0.5-2.5$} \\
\hline Unadjusted HR & & $1.2(0.6-2.3)$ & $3.0(1.5-6.0)$ \\
\hline Adjusted HR* & & $1.0(0.5-2.0)$ & $2.5(1.2-4.9)$ \\
\hline \multicolumn{4}{|c|}{ Comparison to $\mathrm{TSH}=2.5-5.0$} \\
\hline Unadjusted HR & & & $2.6(1.4-5.0)$ \\
\hline Adjusted HR* & & & $2.5(1.3-4.7)$ \\
\hline
\end{tabular}

*Adjustment for age, gender, malignancy, ischemic heart disease, congestive heart failure, hypertension, diabetes, chronic renal failure and cerebrovascular disease.

\section{Free T4 levels and mortality}

fT4 levels after discharge and throughout the follow-up were available for 440 patients, with 32\% all-cause mortality at the end of follow-up (140/440 patients). Most patients had median fT4 levels in the normal range (10-20 pmol/L). Median fT4 levels were categorized as follows: less than $10 \mathrm{pmol} / \mathrm{L}(n=8,1 \%), 10-15 \mathrm{pmol} / \mathrm{L}$ $(n=211,47 \%), 15-20 \mathrm{pmol} / \mathrm{L}(n=191,45 \%)$ and above $20 \mathrm{pmol} / \mathrm{L}(n=30,7 \%)$.

Unadjusted hazard ratios (95\% CI) of all-cause mortality compared to median fT4 levels between 10 and $15 \mathrm{pmol} / \mathrm{L}$ were $1.1(0.8-1.5)$ for median fT4 levels between 15 and $20 \mathrm{pmol} / \mathrm{L}, 0.9$ (0.4-1.9) for fT4 levels above $20 \mathrm{pmol} / \mathrm{L}$ and $1.2(0.4-3.7)$ for median fT4 levels less than $10 \mathrm{pmol} / \mathrm{L}$. After adjustment, respective hazard ratios were 1.1 (0.8-1.6), 1.2 (0.6-2.5) and $1.7(0.5-5.4)$. The trend was similar with mean fT4 levels and minimal fT4 levels during follow-up. Median survival time after discharge was similar in patients with median fT4 levels of 10-15 pmol/L (1137 days, range 92-1940 days) and fT4 levels of 15-20 (1145 days, range 65-1614 days)
(Fig. 3). However, there was a marked difference in median time to death: 784 days (92-1401 days) with fT4 10-15 pmol/L compared to 548 days (65-1423 days) with fT4 15-20 pmol/L.

\section{Free T4, TSH levels and mortality}

Levels of both TSH and fT4 during follow-up were available for 440 patients. Due to the small number of patients with $\mathrm{fT} 4<10 \mathrm{pmol} / \mathrm{L}$ and $\mathrm{fT} 4>20 \mathrm{pmol} / \mathrm{L}$, we $\mathrm{did}$ not analyze the data for these groups. Consequently, we analyzed the data for 358 patients with median TSH levels between 0.5 and 10IU/L and median fT4 levels between 10 and $20 \mathrm{pmol} / \mathrm{L}$. Patients were classified according to median TSH and fT4 levels as follows:

- Median TSH levels of 0.5-2.5 IU/L:

- With median fT4 levels between 10 and $15 \mathrm{pmol} / \mathrm{L}$ $(n=59,16 \%)$.

- With median fT4 levels between 15 and $20 \mathrm{pmol} / \mathrm{L}$ $(n=61,17 \%)$

- Median TSH levels of 2.5-5.0 IU/L:

- With median fT4 levels between 10 and $15 \mathrm{pmol} / \mathrm{L}$ ( $n=89,25 \%)$.

- With median fT4 levels between 15 and $20 \mathrm{pmol} / \mathrm{L}$ $(n=74,21 \%)$

- Median TSH levels of 5-10IU/L:

- With median fT4 levels between 10 and $15 \mathrm{pmol} / \mathrm{L}$ $(n=39,11 \%)$.

- With median fT4 levels between 15 and $20 \mathrm{pmol} / \mathrm{L}$ $(n=36,10 \%)$

All-cause mortality rates at the end of follow-up were $31 \%$ (108/358 patients). As shown in Table 2, the highest mortality rates were evident in patients with median TSH levels between 5 and 10IU/L and median fT4 levels between 15 and 20 pmol/L (18/36 patients, 50\%), and in those with median TSH levels between 5 and $10 \mathrm{IU} / \mathrm{L}$ and median fT4 levels between 10 and 15 pmol/L (18/39 patients, 46\%). Mortality rates were lower in patients with other combinations of median TSH and fT4 levels.

With median fT4 levels between 10 and $15 \mathrm{pmol} / \mathrm{L}$, the adjusted hazard ratio with median TSH levels between 5.0 and $10.0 \mathrm{IU} / \mathrm{L}$ was significant compared to median TSH levels between 0.5 and $2.5 \mathrm{IU} / \mathrm{L}(2.2,1.0-4.3)$ and compared to median TSH levels of $2.5-5.0 \mathrm{IU} / \mathrm{L}(2.2$, 1.2-4.3) (Table 2). With median fT4 levels between 15 and $20 \mathrm{pmol} / \mathrm{L}$, the adjusted hazard ratios with median TSH levels between 5.0 and 10.0 IU/L were 2.5 (1.2-4.9) and 2.5 (1.3-4.7) compared to median TSH levels between 0.5-2.5 IU/L and 2.5-5.0 IU/L, respectively. There was no significant difference between patients with median TSH levels of $5.0-10.0 \mathrm{IU} / \mathrm{L}$ and fT4 levels of $10-15 \mathrm{pmol} / \mathrm{L}$ 
A

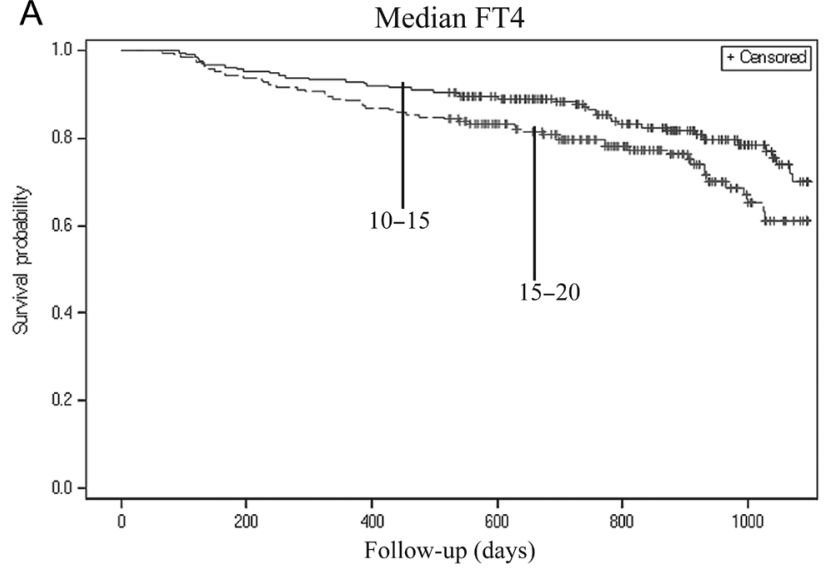

C

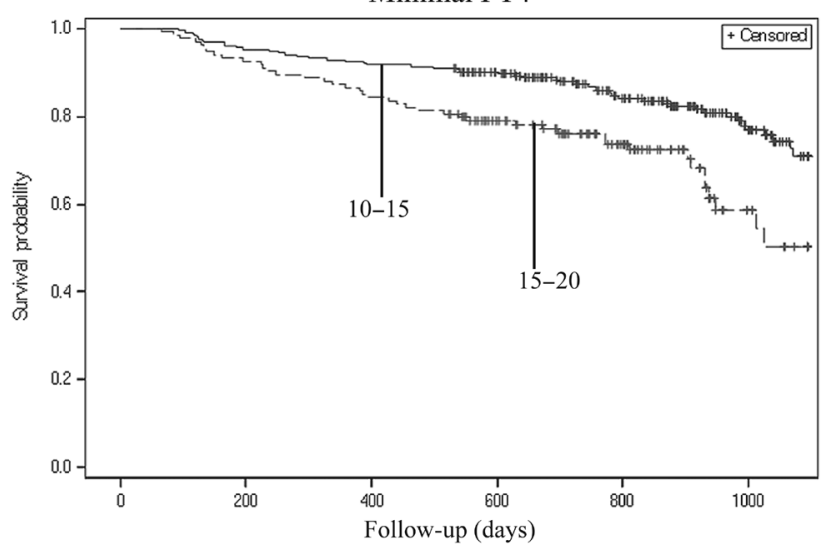

B

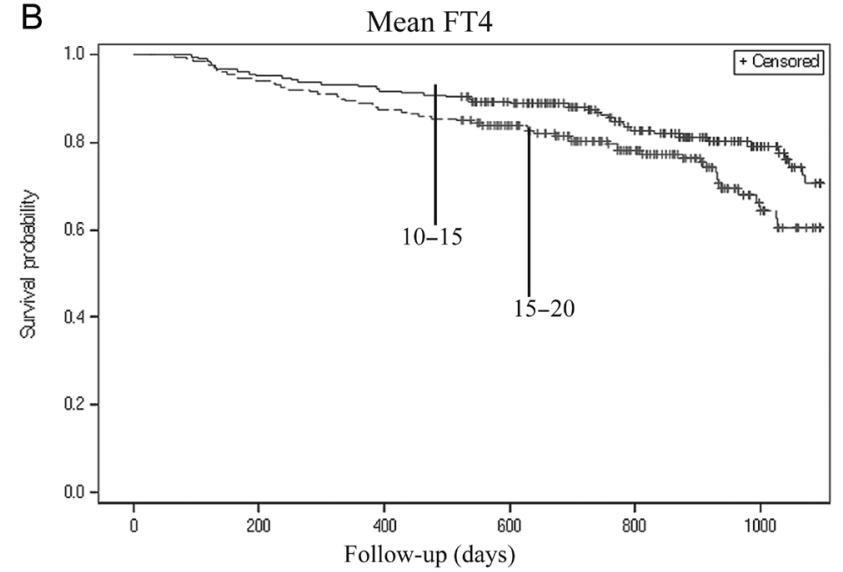

D

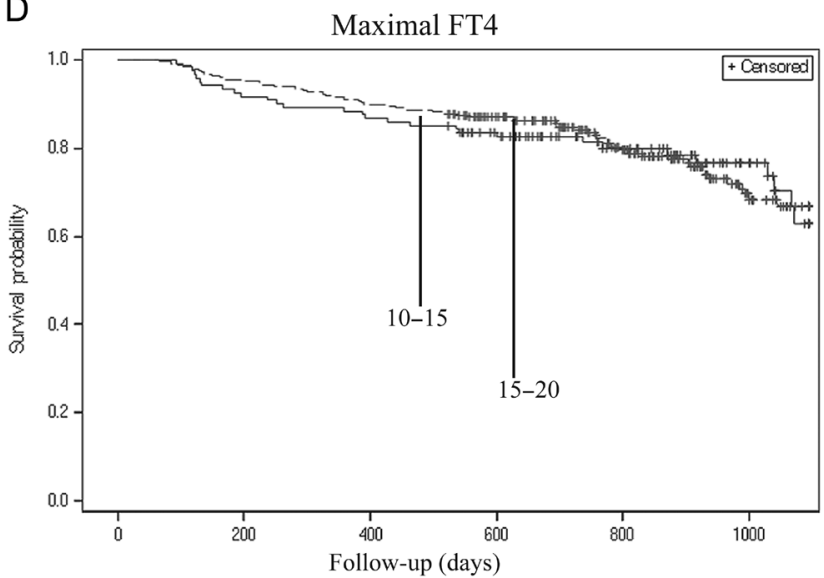

\section{Figure 2}

Kaplan-Meier analysis of patients according to TSH levels during follow-up: (A) median TSH levels, (B) average TSH levels, (C) minimal TSH levels and (D) maximal TSH levels. $P<0.05$ for comparison between median, mean and minimal TSH levels of $0.5-2.5$ and 5.0-10.0 IU/L and $P<0.05$ for comparison between median, mean and minimal TSH levels of 2.5-5.00 and $5.0-10.0 \mathrm{IU} / \mathrm{L}$.

compared to that of patients with median TSH levels of 5.0-10.0 IU/L and median fT4 levels of 15-20 pmol/L.

Kaplan-Meier analysis of patient survival after admission demonstrated the highest survival rates during follow-up for patients with median TSH levels below 5.0 IU/L with fT4 levels between 10-15 and $15-20 \mathrm{pmol} / \mathrm{L}$. The lowest survival rates during follow-up were evident with median TSH levels between 5.0 and $10.0 \mathrm{IU} / \mathrm{L}$ with median fT4 between $10-15$ and 15-20 pmol/L (Fig. 4).

Median survival time after discharge in patients with median TSH of 5.0-10.0IU/L and fT4 levels of 10-15 pmol/L was 1101 days (range 92-1627 days) and in patients with TSH 5.0-10.0 and fT4 levels 15-20 was 972 days (range 116-1539 days). Median time to death was 783 days (92-1168 days) with TSH 5.0-10.0 IU/L and
fT4 $10-15 \mathrm{pmol} / \mathrm{L}$ compared to 548 days (116-1026 days) with TSH 5.0-10.0 IU/L and fT4 15-20 pmol/L.

\section{Discussion}

Our study investigates thyroid function tests in levothyroxine-treated adults, with serial measurements of TSH and fT4 levels during a follow-up of up to 5.5 years. Results indicate that in adult patients with medically treated hypothyroidism and serial measurements of thyroid function tests, mortality rates are higher with median TSH levels above the normal range, with no significant difference between patients with median fT4 levels in the upper or lower normal range. Exploring the minimal and average TSH levels during follow-up proved a similar trend. 


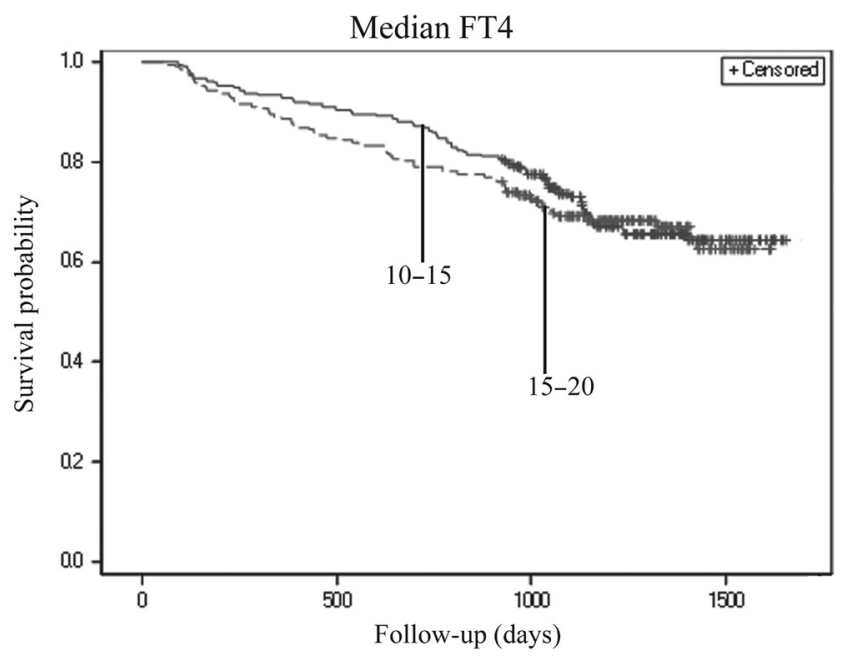

Figure 3

Kaplan-Meier analysis of patients according to median fT4 levels during follow-up.

Although several studies investigated the effects of subclinical and overt hypothyroidism on mortality, and others investigated the significance of single measurement

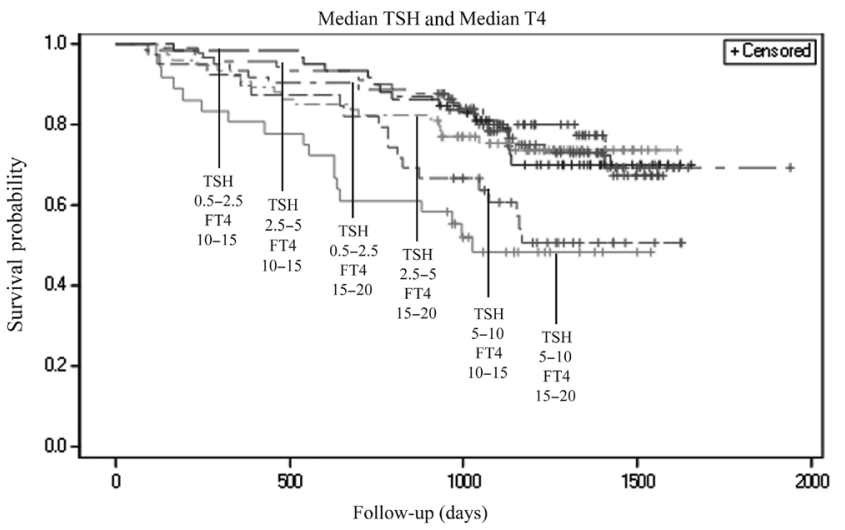

Figure 4

Kaplan-Meier analysis of patients according to median TSH and median fT4 levels during follow-up. Combinations of TSH 5.0-10.0 IU/L and fT4 15-20 pmol/L were statistically significantly different compared to all combinations $(P<0.05)$, other than combination of TSH 5.0-10.0 IU/L and fT4 10-15 pmol/L. Combinations of median TSH levels between 5.0 and $10.0 \mathrm{IU} / \mathrm{L}$ and median fT4 levels between 10 and $15 \mathrm{pmol} / \mathrm{L}$ were statistically significantly different compared to combination of median TSH levels between 0.5 and 2.5IU/L and fT4 levels between 15 and $20 \mathrm{pmol} / \mathrm{L}$, and compared to median TSH levels between 2.5 and 5.0 IU/L and median fT4 levels between 10 and $15 \mathrm{pmol} / \mathrm{L}$. No significant difference between other combinations. of thyroid function tests, this is the first study to focus on levothyroxine-treated adult patients with repeated measurements of thyroid function tests $(4,6,7,8,9,10$, $11,12,13,14,15,16,17$ ) (Table 3).

The results of a recent retrospective study to evaluate the association between subclinical hypothyroidism and all-cause mortality indicated decreased mortality with TSH levels between 5 and 10 IU/L with a potential protective effect of subclinical hypothyroidism in the general population (23). However, our results indicate that with levothyroxine treatment for hypothyroidism, these elevated TSH levels are associated with increased mortality. The increased mortality in treated patients with increased TSH levels could reflect a more general tendency to delay medical care or a low compliance to medical treatment, associated with uncontrolled hypothyroidism, as well as other uncontrolled comorbidities. Furthermore, high TSH levels have been associated with chronic kidney disease and abnormal lipid profile $(24,25)$. In the presence of multiple comorbidities in elderly patients, it is even more difficult to define the association between thyroid function and mortality, though in this study we adjusted for most risk factors associated with excess mortality in this population.

Although the upper normal range for TSH levels are between 4.5 and $5.0 \mathrm{IU} / \mathrm{L}$, some experts have suggested that the true upper limit is only 2.5 or $3 \mathrm{IU} / \mathrm{L}$ in healthy individuals without thyroid disease, whereas others maintain that the serum TSH distribution shifts toward higher values with age, independent of the presence of antithyroid antibodies (26). Our results did not indicate any difference in all-cause mortality between levothyroxine-treated patients with median TSH levels between $0.5-2.5$ or $2.5-5.0 \mathrm{IU} / \mathrm{L}$, thus supporting the use of the current accepted threshold.

Yeap et al. reported that higher fT4 levels are associated with all-cause mortality in euthyroid older men (27). Other studies reported an association between highnormal fT4 levels and risk of atrial fibrillation and low bone mineral density $(28,29,30)$. Furthermore, a recent study demonstrated better mobility, fitness and fatigue profiles in older adults with low-normal fT4 levels (31). We could not identify a similar difference in mortality between patients with median fT4 levels in the upper or lower half of the normal range. Accordingly, the highest mortality rates were documented in patients with median TSH levels above the normal range with median fT4 levels in the upper or lower half of the normal range, as half of these patients died during follow-up. Importantly, as 

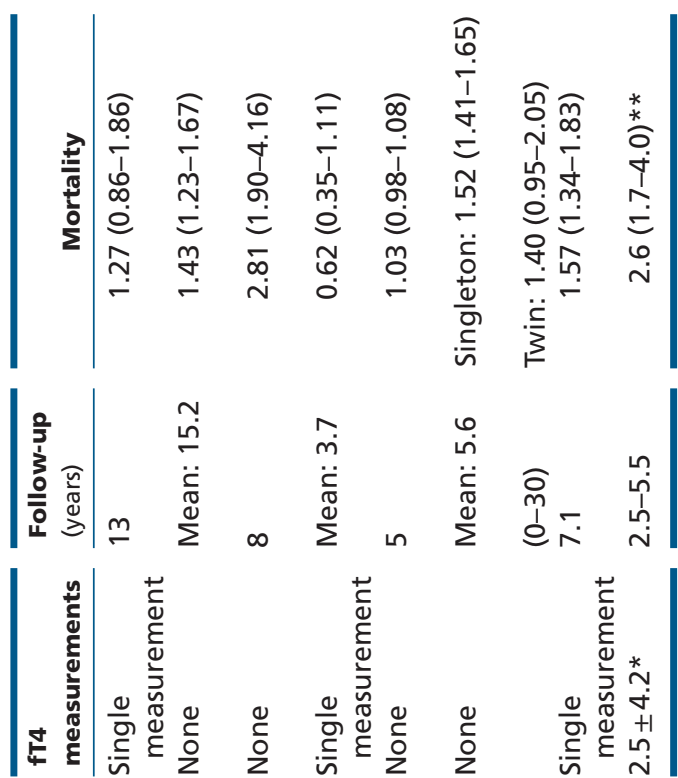

$$
\text { กุ }
$$
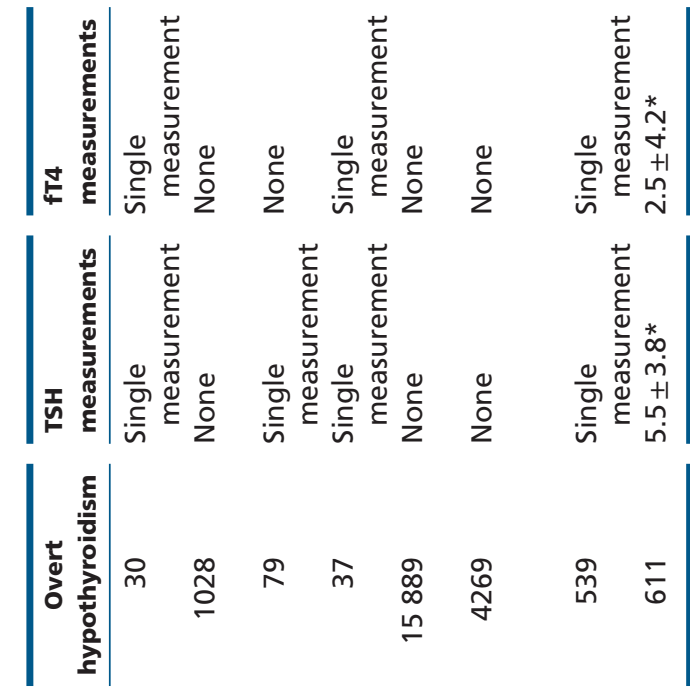

กิ $\bar{\sigma}$

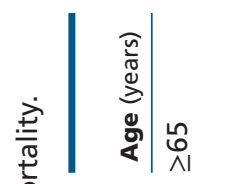

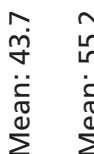

$$
\text { กับ }
$$$$
\text { 車 }
$$

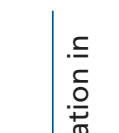

.

응

응

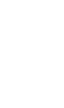

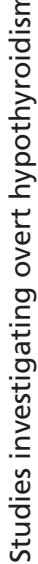



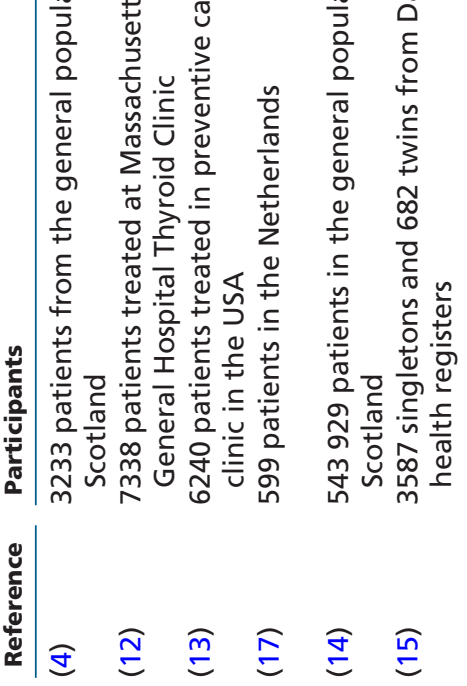

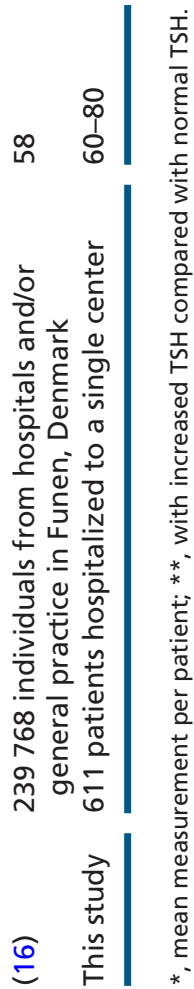

previous studies were based on a single measurement of fT4 levels, our cohort included patients with up to 15 measurements of fT4 levels during follow-up.

However, although there was no difference in mortality at the end of follow-up or median survival with median fT4 $10-15$ or $15-20 \mathrm{pmol} / \mathrm{L}$, we identified a significant early decrease in survival of patients with median fT4 levels between 15 and $20 \mathrm{pmol} / \mathrm{L}$, which faded at the end of follow-up (Fig. 3), and analysis of median time to death proved marked difference (784 days with fT4 levels $10-15$ pmol/L compared to 548 days with fT4 levels $15-20 \mathrm{pmol} / \mathrm{L})$. Similar trend was apparent with a combination of median TSH and fT4 levels. Thus, there is a potential early survival benefit with fT4 levels of $10-15 \mathrm{pmol} / \mathrm{L}$ compared to levels of $15-20 \mathrm{pmol} / \mathrm{L}$, which disappears with long-term follow-up.

The current study has several limitations. First, many patients were excluded from the study as they had no measured thyroid function tests during follow-up. In this regard, we should mention that we collected thyroid function test results at least 30 days after discharge, in an attempt to overcome abnormal results associated with non-thyroidal illness syndrome during admission, thus excluding patients who died during hospitalization or in the following 30 days. Second, as this is not a prospective study, thyroid function tests were completed according to the physician's discretion. Although thyroid function tests were based on blood tests collected in the morning, information regarding the last dose of levothyroxine treatment was not available. Furthermore, data regarding duration of hypothyroidism were not available.

There are several possible explanations for the increased mortality associated with median TSH levels above the normal range, such as poor compliance with medical care, including levothyroxine treatment or more severe comorbidities in the group of patients with increased mortality that will lead to intracellular changes in thyroid hormone metabolism, which are not accounted for with fT4 measurements. Furthermore, it is possible that hypothyroidism per se is responsible for the increased mortality in the group of patients with elevated TSH levels. Although previous studies focused mainly on patients with subclinical hypothyroidism with conflicting results regarding the association between thyroid function and mortality $(6,8,9,10,13)$, we focused on patients aged $60-80$ years with medically treated hypothyroidism, indicating clearly an increased mortality with elevated TSH levels.

Due to the retrospective nature of the study, cause and effect relationship between thyroid function tests

www.eje-online.org 
and mortality cannot be concluded. Although baseline characteristics and comorbidities were generally similar between the TSH categories, malignancy, hypertension and cerebrovascular disease were more common in patients with TSH levels between 5 and 10IU/L, compared to patients with normal TSH levels, highlighting the possibility that in patients with extensive comorbidities, thyroid function levels are not well controlled or associated with lower compliance to treatment. However, the association between elevated TSH levels and mortality was adjusted for the main comorbidities, including those mentioned previously. Furthermore, there was no difference in the number of thyroid tests measured throughout the follow-up between well-controlled patients and those with elevated TSH levels.

In patients with hypothyroidism, the aim of treatment is to achieve euthyroidism, but during longterm follow-up, repeated thyroid function evaluation is crucial to assess changes in thyroid function and adjust treatment accordingly. This is the first study to evaluate the association between serial TSH measurements and mortality, and its results indicate that in patients treated for hypothyroidism, levothyroxine dose should be adjusted to achieve TSH in the normal range, as levels above the normal are associated with increased mortality.

In conclusion, in adult patients with treated hypothyroidism and serial measurements of thyroid function tests during follow-up, median TSH levels above the normal range are associated with increased mortality. There was no difference in survival of patients with median fT4 in the upper or lower half of the normal range, but there was a potential early survival benefit for lower fT4 levels. Treatment with levothyroxine in hypothyroid individuals should thus aim at achieving euthyroidism to improve patients' survival.

\section{Declaration of interest}

The authors declare that there is no conflict of interest that could be perceived as prejudicing the impartiality of the research reported.

\section{Funding}

This research did not receive any specific grant from funding agencies in the public, commercial, or not-for-profit sectors.

\section{References}

1 Iglesias P, Ridruejo E, Muñoz A, Prado F, Macías MC, Guerrero MT, Tajada P, García-Arévalo C \& Díez JJ. Thyroid function tests and mortality in aged hospitalized patients: a 7-year prospective observational study. Journal of Clinical Endocrinology and Metabolism 201398 4683-4690. (doi:10.1210/jc.2012-3849)
2 Empson M, Flood V, Ma G, Eastman CJ \& Mitchell P. Prevalence of thyroid disease in an older Australian population. Journal of Internal Medicine 200737 448-455. (doi:10.1111/j.1445-5994.2007.01367.x)

3 Faggiano A, Del Prete M, Marciello F, Marotta V, Ramundo V \& Colao A. Thyroid diseases in elderly. Minerva Endocrinologica 201136 211-231.

4 Cappola AR, Fried LP, Arnold AM, Danese MD, Kuller LH, Burke GL, Tracy RP \& Ladenson PW. Thyroid status, cardiovascular risk, and mortality in older adults. JAMA 2006295 1033-1041. (doi:10.1001/ jama.295.9.1033)

5 Parle JV, Maisonneuve P, Sheppard MC, Boyle P \& Franklyn JA. Prediction of all-cause and cardiovascular mortality in elderly people from one low serum thyrotropin result: a 10-year cohort study. Lancet 2001358 861-865. (doi:10.1016/S0140-6736(01)06067-6)

6 Grossman A, Weiss A, Koren-Morag N, Shimon I, Beloosesky Y \& Meyerovitch J. Subclinical thyroid disease and mortality in the elderly: a retrospective cohort study. American Journal of Medicine 2016 129 423-430. (doi:10.1016/j.amjmed.2015.11.027)

7 Waring AC, Harrison S, Samuels MH, Ensrud KE, LeBlanc ES, Hoffman AR, Orwoll E, Fink HA, Barrett-Connor E \& Bauer DC. Thyroid function and mortality in older men: a prospective study. Journal of Clinical Endocrinology and Metabolism 201297 862-870. (doi:10.1210/jc.2011-2684)

8 Hyland KA, Arnold AM, Lee JS \& Cappola AR. Persistent subclinical hypothyroidism and cardiovascular risk in the elderly: the cardiovascular health study. Journal of Clinical Endocrinology and Metabolism 201398 533-540. (doi:10.1210/jc.2012-2180)

9 Nanchen D, Gussekloo J, Westendorp RGJ, Stott DJ, Jukema JW, Trompet S, Ford I, Welsh P, Sattar N, Macfarlane PW et al. Subclinical thyroid dysfunction and the risk of heart failure in older persons at high cardiovascular risk. Journal of Clinical Endocrinology and Metabolism 201297 852-861. (doi:10.1210/jc.2011-1978)

10 Lindeman RD, Romero LJ, Schade DS, Wayne S, Baumgartner RN \& Garry PJ. Impact of subclinical hypothyroidism on serum total homocysteine concentrations, the prevalence of coronary heart disease (CHD), and CHD risk factors in the New Mexico Elder Health Survey. Thyroid 200313 595-600. (doi:10.1089/105072503322238863)

11 Ceresini G, Marina M, Lauretani F, Maggio M, Bandinelli S, Ceda GP \& Ferrucci L. Relationship between circulating thyroid-stimulating hormone, free thyroxine, and free triiodothyronine concentrations and 9-year mortality in euthyroid elderly adults. Journal of the American Geriatrics Society 201664 553-560. (doi:10.1111/jgs.14029)

12 Goldman MB, Monson RR \& Maloof F. Cancer mortality in women with thyroid disease. Cancer Research 199050 2283-2289.

13 McQuade C, Skugor M, Brennan DM, Hoar B, Stevenson C \& Hoogwerf BJ. Hypothyroidism and moderate subclinical hypothyroidism are associated with increased all-cause mortality independent of coronary heart disease risk factors: a PreCIS database study. Thyroid 201121 837-843. (doi:10.1089/thy.2010.0298)

14 Thvilum M, Brandt F, Almind D, Christensen K, Hegedüs L \& Brix TH. Excess mortality in patients diagnosed with hypothyroidism: a nationwide cohort study of singletons and twins. Journal of Clinical Endocrinology and Metabolism 201398 1069-1075. (doi:10.1210/ jc.2012-3375)

15 Flynn RWV, Macdonald TM, Jung RT, Morris AD \& Leese GP. Mortality and vascular outcomes in patients treated for thyroid dysfunction. Journal of Clinical Endocrinology and Metabolism 200691 2159-2164. (doi:10.1210/jc.2005-1833)

16 Laulund AS, Nybo M, Brix TH, Abrahamsen B, Jørgensen HL \& Hegedüs L. Duration of thyroid dysfunction correlates with allcause mortality. the OPENTHYRO register cohort. PLOS ONE 20149 e110437. (doi:10.1371/journal.pone.0110437)

17 Gussekloo J, van Exel E, de Craen AJM, Meinders AE, Frölich M \& Westendorp RGJ. Thyroid status, disability and cognitive function, and survival in old age. JAMA 2004292 2591-2599. (doi:10.1001/ jama.292.21.2591) 
18 Cappola AR, Arnold AM, Wulczyn K, Carlson M, Robbins J \& Psaty BM. Thyroid function in the euthyroid range and adverse outcomes in older adults. Journal of Clinical Endocrinology and Metabolism 2015100 1088-1096. (doi:10.1210/jc.2014-3586)

19 Thvilum M, Brandt F, Brix TH \& Hegedüs L. A review of the evidence for and against increased mortality in hypothyroidism. Nature Reviews Endocrinology 20128 417-424. (doi:10.1038/nrendo.2012.29)

20 Ochs N, Auer R, Bauer DC, Nanchen D, Gussekloo J, Cornuz J \& Rodondi N. Meta-analysis: subclinical thyroid dysfunction and the risk for coronary heart disease and mortality. Annals of Internal Medicine 2008148 832-845. (doi:10.7326/0003-4819-148-11200806030-00225)

21 Haentjens P, Van Meerhaeghe A, Poppe K \& Velkeniers B. Subclinical thyroid dysfunction and mortality: an estimate of relative and absolute excess all-cause mortality based on time-to-event data from cohort studies. European Journal of Endocrinology 2008159 329-341. (doi:10.1530/EJE-08-0110)

22 Chen I \& Sperling M. Thyroxine. Clinical Chemistry: Theory, Analysis, Correlation 1989 956-959.

23 Selmer C, Olesen JB, Hansen ML, von Kappelgaard LM, Madsen JC, Hansen PR, Pedersen OD, Faber J, Torp-Pedersen C \& Gislason GH. Subclinical and overt thyroid dysfunction and risk of all-cause mortality and cardiovascular events: a large population study. Journal of Clinical Endocrinology and Metabolism 201499 2372-2382. (doi:10.1210/jc.2013-4184)

24 Zhang Y, Chang Y, Ryu S, Cho J, Lee W-Y, Rhee E-J, Kwon M-J, Pastor-Barriuso R, Rampal S, Han WK et al. Thyroid hormone levels and incident chronic kidney disease in euthyroid individuals: the Kangbuk Samsung Health Study. International Journal of Epidemiology 201443 1624-1632. (doi:10.1093/ije/dyu126)

25 Spadafranca A, Cappelletti C, Leone A, Vignati L, Battezzati A, Bedogni G \& Bertoli S. Relationship between thyroid hormones, resting energy expenditure and cardiometabolic risk factors in euthyroid subjects. Clinical Nutrition 201534 674-678. (doi:10.1016/j. clnu.2014.07.014)

26 Surks MI \& Hollowell JG. Age-specific distribution of serum thyrotropin and antithyroid antibodies in the US population: implications for the prevalence of subclinical hypothyroidism. Journal of Clinical Endocrinology and Metabolism 200792 4575-4582. (doi:10.1210/jc.2007-1499)

27 Yeap BB, Alfonso H, Hankey GJ, Flicker L, Golledge J, Norman PE $\&$ Chubb SAP. Higher free thyroxine levels are associated with allcause mortality in euthyroid older men: the Health In Men Study. European Journal of Endocrinology 2013169 401-408. (doi:10.1530/ EJE-13-0306)

28 Heeringa J, Hoogendoorn EH, van der Deure WM, Hofman A, Peeters RP, Hop WCJ, den Heijer M, Visser TJ \& Witteman JCM. Highnormal thyroid function and risk of atrial fibrillation: the Rotterdam study. Archives of Internal Medicine 2008168 2219-2224. (doi:10.1001/ archinte.168.20.2219)

29 van Rijn LE, Pop VJ \& Williams GR. Low bone mineral density is related to high physiological levels of free thyroxine in perimenopausal women. European Journal of Endocrinology $2014 \mathbf{1 7 0}$ 461-468. (doi:10.1530/EJE-13-0769)

30 Gammage MD, Parle JV, Holder RL, Roberts LM, Hobbs FDR, Wilson S, Sheppard MC \& Franklyn JA. Association between serum free thyroxine concentration and atrial fibrillation. Archives of Internal Medicine 2007167 928-934. (doi:10.1001/ archinte.167.9.928)

31 Simonsick EM, Chia CW, Mammen JS, Egan JM \& Ferrucci L. Free thyroxine and functional mobility, fitness, and fatigue in euthyroid older men and women in the Baltimore longitudinal study of aging. Journals of Gerontology Series A: Biological Sciences and Medical Sciences 201671 961-967. (doi:10.1093/gerona/glv226)

Received 19 August 2016

Revised version received 23 September 2016

Accepted 19 October 2016 